\title{
Parental roles and childhood sun safety
}

\section{Tessa Li Chyin Lim}

\author{
Monash University Malaysia Campus, Malaysia \\ Corresponding author: Tessa Li Chyin Lim, E-mail: tessalim15@gmail.com
}

\begin{abstract}
Statistics by the Centers for Disease Control and Prevention (CDC) in 2013 show that only $10.1 \%$ of adolescents in the United States (U.S.) wear sunscreen regularly when they are outside on a sunny day for more than an hour. Furthermore, the Healthy People 2020 has failed to reach its target to increase the sun protection among teens from $9.3 \%$ in 2009 to $11.2 \%$ by 2020. Ultraviolet radiation (UVR) exposure and sunburns during the age of 10 to 15 is linked to all kinds of skin cancer, in particular malignant melanoma, the second most common cancer among females aged 15 to 29 years old. Studies have also shown that primary school-aged boys and children aged 8 and above are less protected against UVR and have higher reported sunburns. Many sun protection programs focus on children due to their constant exposure to UVR and due to the fact that there is a higher probability that children would change their behavior. As the skin of children is more sensitive to UVR, sun protection should begin in early childhood, an important phase to establish health behaviors and make a difference in children's lives. Parents play an imperative part in promoting childhood sun safety. Promoting this can take several forms: parents setting a good example for their children and parents keeping themselves and their children educated on sun safety. All these are simply yet effective measures which can go a long way in helping to reduce the burden of skin cancer.
\end{abstract}

Key words: Melanoma; Malignant melanoma; Sun protection factor

\section{OPINION ARTICLE}

Statistics by the Centers for Disease Control and Prevention (CDC) in 2013 show that only $10.1 \%$ of adolescents in the United States (U.S.) wear sunscreen regularly when they are outside on a sunny day for more than an hour. Furthermore, the Healthy People 2020 has failed to reach its target to increase the sun protection among teens from $9.3 \%$ in 2009 to $11.2 \%$ by 2020 [1]. Ultraviolet radiation (UVR) exposure and sunburns during the age of 10 to 15 is linked to all kinds of skin cancer, in particular malignant melanoma, the second most common cancer among females aged 15 to 29 years old [2,3]. Studies have also shown that primary school-aged boys and children aged 8 and above are less protected against UVR and have higher reported sunburns [2]. Many sun protection programs focus on children due to their constant exposure to UVR and due to the fact that there is a higher probability that children would change their behavior [4]. As the skin of children is more sensitive to UVR, sun protection should begin in early childhood, an important phase to establish health behaviors and make a difference in children's lives [2].

Acknowledging the essential role of parents, some of the strategies parents can take include setting a good example for their children by reassessing their sun safety practices. A research by Behrens et al. showed that children aged 13 and above have an $85 \%$ increase in the risk of sunburn when parents favor tanned skin [2]. Other literature also shows that the use of indoor tanning among youth is strongly co-related to parental permission as well as parental use of tanning beds [3]. Another research by Mayer et. al (2011) which investigated the extent of tanning among teens aged 14 to 17 years old in various cities in the U.S. found out that about 1 in 5 girls and 3 in 100 boys had used indoor tanning within the last year. The same research found that the use of indoor tanning is predicted by several factors. These include being a white female, parental use and their beliefs on indoor 
tanning. In a nutshell, parents were a major factor in whether their children partake in indoor tanning. This is in line with other research which showed that parents' attitudes can impact their children's future behavior [5]. According to American Cancer Society, youths are especially susceptible to the misleading claims of tanning industry. Some claim that there is no scientific proof about dangers of UV from tanning beds and it is not a big problem and no different from being under the sun. Thus, they have the misconception that melanoma is not a disease of the young. Contrary to all these popular beliefs, frequent exposure of the UVA by indoor tanning before 35 years old increases the risk of melanoma by almost $60 \%$, which is remarkable. In addition, $12.5 \%$ of all indoor tanning-related acute injuries treated in U.S. hospital emergency departments annually is related to adolescents below 18 years old [3]. Therefore, it is important for parents to know about the well-established dangers of UV radiation exposure from tanning beds and be a role model for their children. Short term effects can include syncope, keratitis and corneal burns, sunburn and immune system suppression. On the other hand, long term effects include solar keratosis, premature skin aging, wrinkles, skin and ocular malignancies, and permanent visual loss. Getting a base tan also does not prevent sunburn and it is not possible to get enough Vitamin D from tanning beds. There is also a real risk of addiction to tanning beds [3].

The second point is that parents ought to educate themselves and their children about sun protection. According to Thoonen and colleagues, sun safety measures should focus on both parents and their children and it is warranted that boys have specific stimulation of sun protection. Establishing good childhood sun protection behaviors will increase the likelihood of habitual behavior in the future. It is found that children who reach adolescence have weakened sun-protective attitudes and behaviours [2] . Several studies also found that generally adolescents do not apply sun protection practices consistently. An analysis of literature about children's sun safety which included parental influence over children programs was done by Buller and colleagues. It was concluded that there were better outcomes for the whole family when programs aimed to increase the parents' knowledge about sun protection and focused on behavioral adjustment in order to protect themselves and not just their children [4]. Therefore, parental influence is necessary and should not be taken lightly. The most recommended sun safe behaviors include seeking shade, applying sunscreen and wearing UV-protective outfits with a hat and sunglasses [2]. The CDC recommends indoor activities during mid-day and if possible, seek shade under umbrellas, trees or pop-up tents. Sunscreens must be at least SPF 15, applied half an hour before heading outdoors and reapplied every 2 hours even during cloudy days. There is also another recommendation to cover up with long-sleeved shirts, long pants and skirts which are dry, dark-colored and made from tightly woven fabric. Furthermore, it is recommended that hats should shade the face, scalp, eats and neck [6].

Another way is for parents to educate themselves about sun protection to be able to differentiate facts from myths. These are some of the crucial facts about sun protection according to the Cancer Council Australia. Fact number 1 is that sun damage can still have on cool, windy and cloudy days. Fact number 2 is that a tan does not protect the skin from the sun. Fact number 3 is that people with any skin type can get skin cancer. Fact number 4 is that car window does not prevent sun burns. Fact number 5 is that there is no such thing as a safe tan. Fact number 6 is that skin cancer treatment is more serious than just the removal of lesion. It can include chemotherapy or even surgery. Fact number 6 is that prolonged sun exposure does not increase the Vitamin D levels in the body further. Lastly, sunscreen should not be used to extend the amount of time under the sun [7]. If parents know all these common facts about sun protection, it will most probably benefit their children as well.

In summary, parents play an imperative part in promoting childhood sun safety. Promoting this can take several forms: parents setting a good example for their children and parents keeping themselves and their children educated on sun safety. All these are simply yet effective measures which can go a long way in helping to reduce the burden of skin cancer in the U.S. This is a step in the right direction.

\section{REFERENCES}

1. Centers for Disease Control and Prevention. Sun Protection. https://www.cdc.gov/cancer/skin/statistics/behavior/sunprotection.htm. Accessed January 4, 2020.

2. Thoonen K, Schneider F, Candel M, de Vries H, van Osch L. Childhood sun safety at different ages: relations between parental sun protection behavior towards their child and children's own sun protection behavior. BMC Public Health. 2019;19:1044.

3. American Cancer Society. Just the Facts: Teens and the Dangers of Indoor Tanning. https: / /www.fightcancer.org/sites/default/files/ FINAL $\% 20-\% 20 J u s t \% 20$ the $\% 20$ Facts $\% 20-\% 20$ Teens $\% 20$ and $\% 20$ 
www.odermatol.com

Indoor\%20Tanning\%2006.15.16.pdf. Accessed January 4, 2020.

4. Buller DB, Borland R. Skin cancer prevention for children: A critical review. Health Educat Beh. 1999;26:317-43.

5. Mayer JA, Woodruff SI, Slymen DJ, Sallis JF, Forster JL, Clapp EJ, et al. Adolescents' use of indoor tanning: a large-scale evaluation of psychosocial, environmental, and policy-level correlates. Am J Public Health. 2011;101:930-8.

6. Centers for Disease Control and Prevention. How Can I Protect My Children from the Sun. https://www.cdc.gov/cancer/skin/ basic_info/children.htm. Accessed January 4, 2020.
7. Cancer Council Australia. 10 myths about sun protection. https:// www.cancer.org.au/preventing-cancer/sun-protection/10-mythsabout-sun-protection.html. Accessed January 4, 2020.

Copyright by Tessa Li Chyin Lim. This is an open-access article distributed under the terms of the Creative Commons Attribution License, which permits unrestricted use, distribution, and reproduction in any medium, provided the original author and source are credited.

Source of Support: Nil, Conflict of Interest: None declared. 